\title{
Brain-eating Amoebae Biology and Pathogenesis of Naegleria fowleri
}

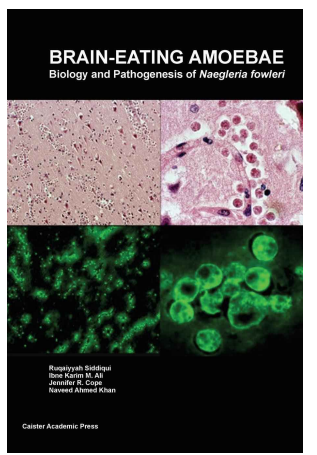

\author{
Author: Ruqaiyyah Siddiqui, Ibne Karim M. Ali, Jennifer R. Cope and Naveed Ahmed \\ Khan \\ Sunway University, Selangor, Malaysia; Centers for Disease Control and Prevention, Atlanta, USA
}

Published: June 2016. Pages: 250

ISBN: Book: 978-1-910190-53-1. Ebook: 978-1-910190-54-8 £159, \$319

Published by: Caister Academic Press www.caister.com

Naegleria fowleri is a eukaryotic protist pathogen that causes primary amoebic meningoencephalitis. It is one of the world's deadliest known parasites with a mortality rate higher than $90 \%$ : infection almost always results in death. A greater scientific understanding of this parasite, how it lives in the environment and its pathogenic mechanism, is crucial for the development of preventative and therapeutic strategies against this fatal, albeit rare disease.

This concise book on $N$. fowleri serves as a quick guide for clinical practitioners, health professionals, researchers and students working with this parasite. Divided into easy-to-follow sections, the book covers all aspects of research into $N$. fowleri as an organism ranging from clinical and laboratory diagnosis to growth and life cycle. It is essential reading for all microbiologists, immunologists, physicians, public health officials and researchers (both new and experienced) involved with $N$. fowleri.

This book is an invaluable reference for everyone working in the field of basic and medical microbiology and a recommended acquisition for all parasitology, microbiology and medical libraries.

\author{
Chapter 0. Introduction to Naegleria \\ Chapter 1. Primary Amoebic Meningoencephalitis \\ Chapter 2. Clinical and Laboratory Diagnosis \\ Chapter 3. Chemotherapeutic and Disinfection Strategies \\ Chapter 4. Pathogenesis \\ Chapter 5. The Host-damage Response to N. fowleri \\ Chapter 6. Cell Biology and Speciation \\ Chapter 7. Cellular Differentiation in N. fowleri \\ Chapter 8. Growth and Lfe Cycle \\ Chapter 9. Ecology \\ Chapter 10. War of the Microbial Worlds \\ Chapter 11. Conclusions and Future Studies
}

Order from:

Caister Academic Press https://www.caister.com/order 


\section{CURRENT BOOKS OF INTEREST}

Porcine Viruses: From Pathogenesis to Strategies for Control

Edited by: Hovakim Zakaryan (Published: 2019)

Lactobacillus Genomics and Metabolic Engineering

Edited by: Sandra M. Ruzal (Published: 2019)

Cyanobacteria: Signaling and Regulation Systems

Author: Dmitry A. Los (Published: 2018)

Viruses of Microorganisms

Edited by: Paul Hyman and Stephen T. Abedon (Published: 2018)

Protozoan Parasitism: From Omics to Prevention and Control

Edited by: Luis Miguel de Pablos Torró and Jacob-Lorenzo Morales (Published: 2018)

Genes, Genetics and Transgenics for Virus Resistance in Plants

Edited by: Basavaprabhu L. Patil (Published: 2018)

DNA Tumour Viruses: Virology, Pathogenesis and Vaccines

Edited by: Sally Roberts (Published: 2018)

Pathogenic Escherichia coli: Evolution, Omics, Detection and Control

Edited by: Pina M. Fratamico, Yanhong Liu and Christopher H. Sommers (Published: 2018)

Postgraduate Handbook: A Comprehensive Guide for PhD and Master's Students and their Supervisors

Author: Aceme Nyika (Published: 2018)

Enteroviruses: Omics, Molecular Biology, and Control

Edited by: William T. Jackson and Carolyn B. Coyne (Published: 2018)

"frontiers in the study of the 12 species of the genus" (ProtoView); "the current most important enterovirus research"

(Biotechnol. Agron. Soc. Environ.)

Molecular Biology of Kinetoplastid Parasites

Edited by: Hemanta K. Majumder (Published: 2018)

Bacterial Evasion of the Host Immune System

Edited by: Pedro Escoll (Published: 2017)

"The figures are expertly drawn" (SIMB News)

Illustrated Dictionary of Parasitology in the Post-Genomic Era

Author: Hany M. Elsheikha and Edward L. Jarroll (Published: 2017)

"a guide for students, academic staff, medical and veterinarian professionals" (ProtoView); "an extensive and comprehensive glossary of contemporary concepts, terminologies, and vocabulary in modern parasitology" (Doodys); "a pure pleasure to explore and discover" (Epidemiol. Infect.); "highly recommended" (Biotechnol. Agron. Soc. Environ.)

Next-generation Sequencing and Bioinformatics for Plant Science

Edited by: Vijai Bhadauria (Published: 2017)

The CRISPR/Cas System: Emerging Technology and Application

Edited by: Muhammad Jamal (Published: 2017)

"reviews recent advances" (ProtoView)

Brewing Microbiology: Current Research, Omics and Microbial Ecology

Edited by: Nicholas A. Bokulich and Charles W. Bamforth (Published: 2017)

"a valuable information source ... an authoritative overview" (IMA Fungus); "a must read book" (SIMB News)

Metagenomics: Current Advances and Emerging Concepts

Edited by: Diana Marco (Published: 2017)

"presents those new to the field with important aspects of metagenomics" (Eur. J. Soil Sci.)

Bacillus: Cellular and Molecular Biology (Third edition)

Edited by: Peter L. Graumann (Published: 2017)

"a one-stop shop for a huge range of Bacillus-focused molecular biology" (Microbiology Today) 